\title{
DISABILITY RIGHTS AND COMPULSORY PSYCHIATRIC TREATMENT: THE CASE FOR A BALANCED APPROACH UNDER THE MENTAL HEALTH (COMPULSORY ASSESSMENT AND TREATMENT) ACT 1992
}

\author{
Toni Wharehoka*
}

\begin{abstract}
This article argues the New Zealand Government's current approach to compulsory psychiatric treatment is unjustifiable in a human rights context. Under s 59 of the Mental Health (Compulsory Assessment and Treatment) Act 1992, clinicians are empowered to administer compulsory psychiatric treatment to individuals without, or contrary to, their consent. This article analyses s 59, and its underlying justifications, in light of the New Zealand Government's commitments under the United Nations Convention on the Rights of Persons with Disabilities (UNCRPD). Further, it analyses the approach for compulsory psychiatric treatment advocated by the UNCRPD in light of Aotearoa New Zealand's mental health context to evaluate whether this approach would be more desirable than the current approach under 5 59. The article then advocates for a more balanced approach to compulsory psychatric treatment which puts the rights of disabled individuals at the forefront and also ensures there are limits to these rights which are justifiable within a human rights context.
\end{abstract}

\section{INTRODUCTION}

Aotearoa New Zealand has some of the most concerning mental health statistics in the Organisation for Economic Cooperation and Development (OECD). Every year, around one in five people experience a diagnosed mental illness or significant mental distress, and around 20,000 people

* Taranaki and Te Ati Awa. Submitted for LLB (Honours) Degree, Victoria University of Wellington 2020. 
attempt to take their own lives. ${ }^{1}$ In 2015 alone, 525 New Zealanders took their own lives. ${ }^{2}$ Mental illness, and especially suicide, impacts the individual who is suffering, their whānau, and the community as a whole. ${ }^{3}$

One strategy the New Zealand Government uses to address these troubling mental health statistics is to make individuals with mental illnesses subject to compulsory psychiatric treatment under s 59 of the Mental Health (Compulsory Assessment and Treatment) Act 1992 (MHA). Section 59 allows a responsible clinician to administer psychiatric treatment to an individual under a compulsory treatment order (CTO) without, and sometimes contrary to, their consent. ${ }^{4}$ This treatment is justified on what the responsible clinician believes to be the "best interests" of the individual. ${ }^{5}$

Section 59 of the MHA is arguably inconsistent with the rights affirmed under the United Nations Convention on the Rights of Persons with Disabilities (UNCRPD). ${ }^{6}$ Section 59 allows the denial of an individual's right to consent to treatment on the grounds that they meet the conditions of "mental disorder". ${ }^{7}$ Denying an individual their rights on this ground is known as substituted decisionmaking. ${ }^{8}$ The United Nations Committee on the Rights of Disabled People (the Committee) General Comment No. 1 (the Comment) argues substituted decision-making models are discriminatory and unacceptable. ${ }^{9}$ Further, the Comment advocates for abolishing substituted decision-making, ${ }^{10}$ which centres on "best interest" assessments, and advocates for supported decision-making processes, which centre around the individual's "will and preference". ${ }^{11} \mathrm{~A}$ "will and preference" assessment allows for the individual's agency to be at the centre of any decision in their life including decisions about

1 He Ara Oranga: Government Inquiry into Mental Health and Addiction (November 2018) at 8.

2 At 8 .

3 At 8

4 A responsible clinician, in relation to a patient, means the clinician in charge of the treatment of that patient.

5 Mental Health (Compulsory Assessment and Treatment) Act 1992, s 59(2)(b); and Ministry of Health Guidelines to the Mental Health (Compulsory Assessment and Treatment Act) 1992 (September 2020) at 2.

6 United Nations Convention on the Rights of Persons with Disabilities UNTS 2515 (opened for signature 30 March 2007, entered into force 3 May 2008), art 12; and Committee on the Rights of Persons with Disabilities General Comment No. 1 UN Doc CRPD/C/GC/1 (19 May 2014) at [7].

7 Mental Health (Compulsory Assessment and Treatment) Act 1992, ss 2 and 27(3).

8 Geneva Richardson "Mental Disabilities and the Law: From Substitute to Supported Decision-Making?" (2012) 65 CLP 333 at 337.

9 Committee on the Rights of Persons with Disabilities General Comment No. 1, above n 6, at [7].

10 At [7].

11 At [26]. 
psychiatric treatment. ${ }^{12}$ Therefore, by embracing a substituted decision-making model under s 59 of the MHA, the New Zealand Government is not living up to its commitments under the UNCRPD.

Previous studies have explored an individual's right to refuse treatment whilst under a CTO and have evaluated the MHA in a human rights context. ${ }^{13}$ However, no study has yet evaluated s 59 specifically in light of the Comment; ${ }^{14}$ nor has there been a discussion around substituted and supported decision-making models in an Aotearoa New Zealand mental health context. Discussions around these decision-making models have been in regard to other areas of law in Aotearoa New Zealand or about mental health law in overseas jurisdictions. ${ }^{15}$

This article, therefore, takes the debate forward by evaluating the New Zealand Government's current practice under s 59 of the MHA, together with the encouraged practice by The United Nations Committee on the Rights of Persons with Disabilities under the Comment, before assessing whether to omit substituted decision-making from psychiatric treatment altogether. There are significant failings in the current legal regime, which makes this debate one of practical rather than mere theoretical importance. Vulnerable members of society are not being materially assisted by s 59 in its current form. Approximately 104 people in every 100,000 are currently subject to compulsory psychiatric treatment under s 59, with these numbers projected to increase absolutely and

12 At [26].

13 See Jeremy Skipworth "Should Involuntary Patients with Capacity Have the Right to Refuse Treatment?" in John Dawson and Kris Geldhill (eds) New Zealand's Mental Health Act in Practice (Victoria University Press, Wellington, 2013) 229; and Kris Gledhill "A 'Rights' Audit of the Mental Health Act" in John Dawson and Kris Geldhill (eds) New Zealand's Mental Health Act in Practice (Victoria University Press, Wellington, 2013) at 285.

14 There have been discussions of the Comment in relation to mental health law generally. See for example John Dawson "A realistic approach to assessing mental health laws' compliance with the UNCRPD" (2015) 40 Int'l J L and Psych 70; and Tina Minkowitz "Abolishing Mental Health Laws to Comply with the Convention on the Rights of Persons with Disabilities" in Bernadette McSherry and Penelope Welter (eds) Rethinking RightsBased Mental Health Laws (Hart Publishing, Portland, 2010) at 151.

15 See for example B Mirfin-Veitch Exploring Article 12 of the United Nations Convention on the Rights of Persons with Disabilities: An Integrative Literature Review (Donald Beasley Institute, 2016); Alison Douglass Mental Capacity: Updating New Zealand's Law and Practice (New Zealand Law Foundation, Dunedin, 2016); Michael Bach and Lana Kezner A New Paradigm for Protecting Autonomy and the Right to Legal Capacity (Law Commission of Ontario, October 2010); Sacha Callaghan and Christopher J Ryan "Rising to the human rights challenge in compulsory treatment - new approaches to mental health law in Australia" (2012) 46 Aust NZ J Psychiatry 611; Michael C Dunn and others "Constructing and Reconstructing 'Best Interests': An Interpretive Examination of Substitute Decision-making under the Mental Capacity Act 2005" (2007) 29 J Soc Wel \& Fam L 117; Raymond Lang and others "Implementing the United Nations Convention on the rights of persons with disabilities: principles, implications, practice and limitations" (2011) 5 Alter,European Journal of Disability Research 206; and Richardson, above n 8. 
proportionally to the population. ${ }^{16}$ One reason for this is due to the number of people who are under indefinite orders, making them subject to compulsory treatment for the rest of their lives. ${ }^{17}$ What this illustrates is that the number of people suffering from a mental illness is increasing, not decreasing the system is not working as it should.

The New Zealand Government has recognised the regime under s 59 is failing, and has announced it will eventually repeal and replace the MHA. ${ }^{18}$ How and when it will do this, however, is still unclear. In the interim the Ministry of Health has released updated guidelines to encourage clinicians to better apply the UNCRPD when administering treatment. ${ }^{19}$ However, it has limited the application of the UNCRPD by stating that clincians should consider how to apply the UNCRPD in their practice within the limits of the MHA. ${ }^{20}$ With the MHA itself explicitly restricting the rights of the individual under s 59, the guidelines do not change anything. The use of supported decision-making models is still up to the discretion of the clinician as the New Zealand Government's current regime does not include legal requirements to apply the UNCRPD.

This article argues that the New Zealand Government's current practice under s 59 of the MHA cannot be legitimately justified under human rights law and legislative change is needed. However, adopting the recommendations proposed by the Comment should not be the way forward due to its failure to recognise justified limitations on autonomy and its failure to incorporate indigenous perspectives on autonomy. Working towards a solution which balances both approaches and provides space for te ao Māori definitions of autonomy is the best way forward for mental health law in Aotearoa New Zealand. Part One explains how a CTO is issued under the MHA, the substituted decision-making process within s 59 of the MHA, and the current justifications behind this process. Part Two identifies the development of case law on the justifications for the compulsory treatment process under s 59 to show how these justifications are applied in practice and to create a better understanding on what standards need to be met for an individual's rights to be limited under s 59 . Part Three introduces the UNCRPD and the Comment to discuss how adopting the suggestions in the Comment would impact Aotearoa New Zealand's mental health regime. Part Four evaluates the New Zealand government's current practice and the practice proposed by the Comment and presents a more balanced approach to psychiatric treatment under the MHA.

16 Sarah Gordon "The Recovery of Compulsory Assessment and Treatment" in John Dawson and Kris Gledhill (eds) New Zealand's Mental Health Act in Practice (Victoria University Press, Wellington, 2013) 268 at 277.

17 At 277

18 Ministry of Health Human Rights and the Mental Health (Compulsory Assessment and Treatment) Act 1992 (September 2014) at vii.

19 Ministry of Health, above n 18, at 4.

20 At 4 . 


\section{CTOS IN AOTEAROA NEW ZEALAND}

A CTO, which is issued under s 27 of the MHA, is an inpatient or outpatient order issued by the District Court or Family Court. ${ }^{21}$ This order allows a responsible clinician to administer psychiatric treatment without the consent of the individual under s 59 of the MHA. CTOs expire after six months from the date the CTO was issued. ${ }^{22}$ Two weeks before the expiry of the original CTO, the responsible clinician can apply to the relevant court for an extension of the order for a further six months. ${ }^{23}$ If the responsible clinician applies for a further extension after the previous extension has been issued, the order will be indefinite, and the individual will be subject to compulsory psychiatric treatment unless or until they are released from compulsory status. ${ }^{24}$

This part of the article explains the process for issuing a CTO and administering compulsory psychiatric treatment. It then describes the justifications behind administering said treatment.

\section{A Issuing a CTO}

Any person who believes an individual is suffering from a mental disorder may at any time fill out a form asking the Director of Area Mental Health Services (the Director) for an assessment of the individual. ${ }^{25}$ This form requires a certificate by a health practitioner who can be a medical practitioner, a nurse practitioner, or a registered nurse practising in mental health stating that there are reasonable grounds to believe an individual has a mental disorder after they have examined that individual. ${ }^{26}$

After the application form has been received by the Director and before a CTO can be legally issued, the individual must go through three different assessment stages. The first stage is a preliminary assessment examination conducted by a health practitioner. ${ }^{27}$ This health practitioner needs to be a psychiatrist approved by the Director or, if no such psychiatrist is readily available, a medical practitioner or nurse practitioner who, in the opinion of the Director, is suitably qualified to conduct the assessment examination. ${ }^{28}$ After this assessment examination, the health practitioner will issue a certificate of preliminary assessment stating whether, in their opinion, the individual falls

\footnotetext{
21 Mental Health (Compulsory Assessment and Treatment) Act 1992, s 27(3).

22 Sections 28(1) and 33.

23 Sections 34(1) and (2).

24 Section 34(4).

25 Section $8 \mathrm{~A}$

26 Section $8 \mathrm{~B}$

27 Section 9(1).

28 Sections 9(3)(a) and 9(3)(b).
} 
within the definition of mentally disordered under the MHA. ${ }^{29}$ "Mental disorder" is defined under the MHA as: ${ }^{30}$

... an abnormal state of mind (whether of a continuous or an intermittent nature), characterised by delusions, or by disorders of mood or perception or volition or cognition, of such a degree that it-

(a) poses a serious danger to the health or safety of that person or of others; or

(b) seriously diminishes the capacity of that person to take care of himself or herself.

If the health practitioner believes the individual does have a mental disorder, the individual will undergo compulsory treatment and assessment for five days. ${ }^{31}$

The second stage involves issuing a certificate of further assessment. Within the five days of compulsory assessment and treatment, the responsible clinician will issue a certificate advising whether, in their opinion, they believe an individual has a mental disorder as defined under the MHA. ${ }^{32}$ If the responsible clinician believes the individual meets this definition, they will be subject to compulsory assessment and treatment for a further 14 days. ${ }^{33}$ Within the first and second stages, the individual, or any other person of interest stipulated in ss 10(4) and 12(5), has the right to get the court to review the individual's condition. ${ }^{34}$

The final stage involves the responsible clinician assessing whether the individual is fit to be released from compulsory status. If they do not believe the individual is fit to be released from compulsory status, due to their mental disorder, the responsible clinician must apply for a CTO under Part 2 of the MHA. ${ }^{35}$ Once this application is received, the court must examine the patient, as well as consult with the responsible clinician and one other health practitioner in the case. ${ }^{36}$ When the application is heard, the individual, or their representatives, has the right to be heard and call evidence. ${ }^{37}$ After examining the individual's condition, the court will consider whether a patient is

29 Section 10(1).

30 Section 2.

31 Section 11.

32 Section 12(1).

33 Section 13.

34 Section 16.

35 Section 14(1).

36 Section 18

37 Section 20 
mentally disordered or not. ${ }^{38}$ If they believe the patient is mentally disordered, they must decide, having regard to all the circumstances, whether a CTO is necessary and should be issued. ${ }^{39}$

\title{
B Section 59 and Substituted Decision-making: Treatment While Subject to a CTO
}

Section 59 is the main provision relied upon by a responsible clinician when administering treatment under a CTO. This provision empowers responsible clinicians to administer any psychiatric treatment, excluding electro-convulsive therapy or brain surgery, to an individual under a CTO ${ }^{40} \mathrm{It}$ falls under Part 5 of the MHA which outlines what processes a responsible clinician needs to go through to administer certain types of treatment. Once someone falls under a CTO, s 59 is the most important provision in the MHA for clinicians administering treatment; the parts before this outline the process for issuing a CTO, whilst the parts after outline the patient's right to judicial review. ${ }^{41}$

Section 59 outlines the process that a responsible clinician must follow when administering compulsory psychiatric treatment under a CTO. It shows the low level of consent needed for treatment to be administered. Within the first month of a CTO, s 59(1) allows the responsible clinician to administer treatment without needing to explain the treatment to the individual or seek the individual's consent. After the first month, s 59(2) obligates the responsible clinician to explain the treatment to the individual and attempt to obtain the individual's written consent. ${ }^{42}$ The Ministry of Health Guidelines (the Guidelines) for seeking consent under s 59(2) explain that consent is not interpreted as free, prior and informed consent. ${ }^{43}$ Instead, consent means "assent", which allows for a level of coercion. $^{44}$

If the individual refuses to consent to the treatment, the proposed treatment will then be reviewed by a psychiatrist, appointed by the Mental Health Review Tribunal (the Tribunal) for a second opinion. ${ }^{45}$ The psychiatrist will assess whether the treatment being proposed by the responsible clinician is in the individual's "interests". ${ }^{46}$ The psychiatrist provides no opinion on whether the

\author{
38 Section 27(1). \\ 39 Section 27(3). \\ 40 See ss 60 (electro-convulsive therapy) and 61 (brain surgery). \\ 41 See generally Parts 1-4 and 6-9. \\ 42 Section 59(2)(a) \\ 43 Ministry of Health, above n 5, at 90 \\ 44 At 90 . \\ 45 Section 59(2)(b). \\ 46 Section 59(2)(b).
}


patient should remain under a CTO or not; they are only required to consider whether they believe the treatment is appropriate.

If the psychiatrist believes the treatment is in the "best interests" of the patient, the treatment will go ahead. ${ }^{47}$ The Guidelines set out what this second opinion needs to consider. The psychiatrist examines the individual's history and assesses the relative risks and benefits of the potential treatment approaches. ${ }^{48}$ Concerning the treatment proposed by the responsible clinician, the psychiatrist will assess whether this is the least restrictive treatment, whether it is of maximal benefit to the individual's condition and whether the treatment is necessary to achieve the purpose of compulsory treatment. ${ }^{49}$

The process stipulated by s 59 is an example of substituted decision-making. Substituted decisionmaking is when decisions are made in the "best interests" of an individual who has crossed a "legally defined border". ${ }^{50}$ In the context of the MHA, this border is the definition of "mental disorder". ${ }^{51}$ Section 59 entails processes which allow a responsible clinician to administer psychiatric treatment if they, and/or a psychiatrist, believe it is in the "interests" of the individual. ${ }^{52}$ This substituted decisionmaking process will not stop unless and until the individual is released from compulsory status under the MHA.

\section{Justifications Behind Substituted Decision-making Under s 59}

There are two main ways substituted decision-making, and the restriction of an individual's autonomy under s 59, may be justified under the MHA. First is the protection of the individual and others in the community from harm. Secondly, the concept of parens patriae stipulates the government's responsibility to help people who cannot help themselves. This section explains the historical origin of these justifications and where these justifications present themselves within the MHA.

47 Section 59; and Ministry of Health, above n 5, at 2 and 91.

48 Ministry of Health, above n 5, at 92

49 At 92.

50 Richardson, above n 8, at 337.

51 Defined in $\mathrm{s} 2$.

52 Ministry of Health, above n 5, at 91. 


\section{Protection from harm}

In relation to health risks, preventing harm is one of the most politically compelling reasons to limit an individual's autonomy. ${ }^{53}$ This justification can be traced back to the liberal philosopher, John Stuart Mill, and his harm principle. ${ }^{54}$ Mill explains this principle by arguing: 55

[T]he only purpose for which power can be rightfully exercised over any member of a civilized community, against his will, is to prevent harm to others. His own good, either physical or moral, is not a sufficient warrant.

Despite Mill making it clear the state can only intervene with an individual's liberty to prevent harm to others, the definition of the harm principle has been expanded to justify state intervention to prevent harm to oneself. Since Mill does not define what "harm to others" means in this principle, it has been open to interpretation and expansion. ${ }^{56}$ Theoretically, there is not much individual conduct which does not harm other people indirectly. ${ }^{57}$ In the mental health context, it has been demonstrated that suicide, which is a harm to oneself, negatively impacts family, whānau, and the community as a whole. $^{58}$

In the MHA, both the traditional and expanded definition of the harm principle is present in its justification of s 59. To fall under a CTO, and thus receive compulsory treatment, an individual must meet the definition of "mental disorder". ${ }^{59}$ The MHA stipulates that the first limb of this definition is that an individual "poses a serious danger to the health or safety of that person or of others". 60 The traditional definition of the harm principle is applicable because one justification for placing an individual under a CTO is if they pose a serious danger to others. This traditional aspect can also apply to the part of the definition which stipulates an individual has a "mental disorder" if they pose a serious danger to themselves. Under the Guidelines, serious danger to the individual may arise when the mental state of that person can make them vulnerable to violent or sexual exploitation from

53 Thaddeus Mason Pope "Balancing Public Health against Individual Liberty: The Ethics of Smoking Regulations" (2000) 61 U Pitt L Rev 419 at 433.

54 See John Stuart Mill On Liberty (Batoche Books, Ontario, 2001).

55 At 13.

56 Editors, Law Review "Limiting the State's Police Power: Judicial Reaction to John Stuart Mill" (1970) 37 U Chi L Rev 605 at 621.

57 Pope, above n 53, at 447; see also Isaiah Berlin "Two Concepts of Liberty" in Four Essays on Liberty (Oxford University Press, Oxford, 1969) 118 at 155.

58 He Ara Oranga, above $\mathrm{n} 1$, at 8.

59 See generally Mental Health (Compulsory Assessment and Treatment) Act 1992, ss 2, 27(1) and 59.

60 Section 2. 
others. ${ }^{61}$ However, the literal meaning of "danger to ... that person" embraces the more expansive definition. Acts, such as self-harm, may make someone fall under a CTO as these are a danger to the individual that may indirectly harm the people around them.

\section{Parens patriae}

Parens patriae is another doctrine the state uses to justify compulsory psychiatric treatment under the MHA. The doctrine is inherently paternalistic and requires the state to act as a protector of individuals who are too vulnerable to protect themselves. ${ }^{62}$ It allows the state to make decisions in the "best interest" of the person to promote and protect their wellbeing, but in the process, overriding their autonomy. ${ }^{63}$ In the MHA, the doctrine of parens patriae is present under the definition of "mental disorder". ${ }^{64}$ If an individual does not meet the requirement of posing a serious danger to themselves or others, the second limb of "mental disorder" stipulates that an individual can still be subject to compulsory psychiatric treatment if their mental state "seriously diminishes the capacity of that person to take care of himself or herself". ${ }^{65}$ This definition allows an individual to be subject to compulsory psychiatric treatment if the person does not have the opportunity to have a minimally accepted standard of life. ${ }^{66}$

\section{JUDICIAL DEVELOPMENT OF S 59 JUSTIFICATIONS}

The justifications for treatment under s 59 have been open to interpretation by the courts due to the wording of these justifications in the MHA. The following sections explain how the courts have interpreted the major justifications and how these justifications apply in practice. Exploring the contextual operation of these two justifications helps provide a better platform for analysing the MHA in light of the New Zealand government's commitments under the UNCRPD. It does this by creating an understanding of what standards need to be met in order for an individual to have their rights limited under s 59.

\section{A Development of the Serious Danger Standard}

Within the first few years of case law surrounding the interpretation of the MHA, the "serious danger" standard was contested between the courts with some interpretations holding "serious danger" to a high standard and others holding it to a lower and more holistic standard. The serious danger

61 Ministry of Health, above n 5, at 15.

62 Bruce J Winick "On Autonomy: Legal and Psychological Perspectives" (1992) 37 Vill L Rev 1705 at 1772.

63 At 1772 .

64 Mental Health (Compulsory Assessment and Treatment) Act 1992, s 2.

65 Section 2.

66 Matthew McKillop "Seriously Diminished Capacity for Self-Care" in John Dawson and Kris Gledhill (eds) New Zealand's Mental Health Act in Practice (Victoria University Press, Wellington, 2013) 77 at 77. 
standard, which is found within the definition of "mental disorder", embraces the harm principle justification for compulsory psychiatric treatment under s 59. Overall, the courts ended up adopting the lower standard. As a result, this justifies compulsory psychiatric treatment under s 59 if an individual presents a threat of danger of low seriousness or low imminence.

The first few cases which tackled the MHA interpreted serious danger in s 2 to mean a serious imminent threat of physical violence to the individual or others. In the case of $\operatorname{Re} O$, the District Court held that serious danger meant "imminent or demonstrable" and that the inclusion of the adjective "serious" meant the test needed to be a strict one. ${ }^{67}$ In Re $M$, Gallen J concluded that serious danger meant a "risk of serious physical violence" and not a "mere nuisance" - this formulation ensures that detention under a CTO is not arbitrary. ${ }^{68}$ This risk of physical violence was also emphasised in Re JK $(J K)$ where Judge Ellis held that physical violence could be actual violence "of such a level of seriousness as to require the detention of the subject irrespective of his state of mind" or potential violence that was "imminent and sufficiently likely as to justify preventative action by way of detention". 69

However, this higher standard was ultimately overruled by a separate line of cases which adopted a more expansive view of serious danger. Under this approach, the courts interpreted serious danger to be a lower standard that justifies non-consensual psychiatric treatment based on less serious and less imminent threats of danger. In $R e T$, the Tribunal rejected the interpretation of serious danger advanced in $J K$ as it believed that compulsory treatment would only be restricted to people who were likely to be incarcerated in the criminal justice system. ${ }^{70}$ The Tribunal shifted the focus of the serious danger assessment from detention to treatment. This is due to the nature of a CTO, which subjects an individual to compulsory psychiatric treatment, not always compulsory detention. ${ }^{71}$ The Tribunal ruled that one of the tests for the serious danger standard was "danger ... likely to happen at any moment in the foreseeable future". ${ }^{72}$ This prediction is to be assessed by reference to four questions concerning the nature of the harm, its imminence, its magnitude, and its frequency. ${ }^{73}$ In that case, $\mathrm{T}$ had not exhibited any recent incidents of dangerous behaviour, but the Tribunal held that the danger test was met. ${ }^{74}$ The Tribunal held that although the lack of recent incidents was a significant factor, it
$67 \operatorname{Re} O$ [1993] NZFLR 545 (DC) at 546.
$68 \operatorname{Re} M[1992] 1$ NZLR 29 (HC) at 39.
$69 \operatorname{Re} J K$ [1994] NZFLR 678 (FC) at 702.
$70 \operatorname{Re} T$ [1994] NZFLR 946 (MHRT) at 953.
71 At 953
72 At 955 .
73 At 951 .
74 At 957 
needed to be balanced against the preventative effects of the medication given, the likelihood of deterioration of T's condition if medication was not voluntarily taken and the likelihood of relapse into dangerous behaviour which posed harm to others, even if this behaviour was not criminal. ${ }^{75}$

\section{$B$ Development of the Self-Care Standard}

Like the "serious danger" standard, the " self-care" standard was also open to interpretation by the courts and it was decided that this standard embraces an objective test with a subjective element. The self-care standard is present within the second limb of the definition of "mental disorder" under s 2 of the MHA and embraces the parens patriae justification for compulsory psychiatric treatment under $\mathrm{s}$ 59. The standard allows for compulsory psychiatric treatment if an individual's mental illness seriously diminishes their capacity to have a minimally acceptable standard of living. On its face, a minimally acceptable standard of living may mean access to the bare necessities of life. However, because there is no concrete definition of a minimally acceptable standard of living, the courts extended this definition to include other aspects of modern living such as family, social relationships, maintaining housing, employment, and physical and mental health.

$\operatorname{Re} C$ demonstrates how the courts assess a minimally accepted standard of self-care. ${ }^{76}$ The Court stated that although it is important to obtain evidence on how an individual had been functioning properly in their social realm compared to how they are functioning now, a court "should objectively assess what an ordinary citizen would find acceptable as a minimum standard of effective self-care for a person of the patient's circumstances and background". ${ }^{77}$ This shows an objective standard with a subjective element. However, the Tribunal has suggested that, in practice, there is a commonality in cases that fall under the self-care provision. ${ }^{78}$ This suggests that an objective standard alone is sufficient, and there is usually no need to engage with the subjective element. ${ }^{79}$

The case of $R e K B L G$ shows how this assessment is applied in practice. ${ }^{80} \mathrm{G}$ had previously demonstrated danger to others and himself when acutely unwell. The Tribunal did not see this as necessary to constitute a serious danger. However, the Tribunal still put G under a CTO, justifying this based on the self-care provision. $G$ would go through periods of self-isolation, which the Tribunal held would seriously diminish the capacity for self-care if his mother and others withdrew their

75 At 957

$76 \operatorname{Re} C$ DC Auckland CAT 132/99, 28 August 2000

77 At 10.

$78 \operatorname{Re}$ AVHM MHRT 08/110, 25 August 2008 at [39].

79 McKillop, above n 66, at 85.

80 Re KBLG MHRT 12/090, 15 August 2012. 
support. Therefore, it was G's inability to maintain relationships which made him subject to a CTO. ${ }^{81}$ Re KBLG indicates the parens patriae justification goes beyond ensuring an individual has the bare necessities of life but extends to other aspects of modern living.

Overall, the interpretations of these standards through case law show how limitations on an individual's autonomy, by making them subject to compulsory psychiatric treatment under s 59, are justified in practice. Both the serious danger standard, which embraces the harm principle, and the self-care standard, which embraces parens patriae, have the effect of making it easier to justify the limitation of an individual's rights. The next part of this article explains what rights are directly affected by the justifications under the MHA by introducing the UNCRPD, the rights affirmed under the UNCRPD and how s 59 of the MHA would be viewed in light of the UNCRPD.

\section{UNITED NATIONS CONVENTION ON THE RIGHTS OF PERSONS WITH DISABILITIES}

By signing the UNCRPD, the New Zealand Government committed to protecting and providing resources to ensure that disabled people are afforded the same rights as non-disabled people. The UNCRPD was drafted at a time when disability activists were promoting a shift in perception of people with disabilities; from being seen as welfare-receivers to humans with inherent rights. ${ }^{82}$ At this time there was also a shift in the definition of disability. Instead of defining disability based on a medical model, which viewed disability as an individual problem that prevented people from performing tasks in a "normal way", a social model was preferred by persons with disabilities. ${ }^{83}$ It viewed disability as socially created rather than an individual issue and began to consider how environmental factors failed to cater to a diverse range of individuals, which disabled them. ${ }^{84}$ This social model is evident in New Zealand's Disability Strategy 2016-2026, which defines disability as: ${ }^{85}$

... something that happens when people with impairments face barriers in society; it is society that disables

us, not our impairments, this is the thing all disabled people have in common. It is something that happens

when the world we live in has been designed by people who assume everyone is the same.

81 At 47 .

82 See for example Jerry Alan Winter "The Development of the Disability Rights Movement as a Social Problem Solver" (2003) 23 DSQ 33.

83 At 41

84 Collin Barnes "A working social model? Disability, work and disability politics in the 21st century" (2000) 20 Crit Soc Policy 441 at 444.

85 Office for Disability Issues New Zealand Disability Strategy 2016-2026 (November 2016) at 12. 
The UNCRPD requires the state to commit more resources to disabled people to ensure their rights are as effectively enforced as non-disabled people. ${ }^{86}$ This part of the article outlines art 12 of the UNCRPD and the Comment released by the Committee concerning the application of this article when it comes to decision-making models for disabled individuals. It then discusses the Committee's view of s 59 in relation to the Comment.

\section{A Article 12: Equal Recognition before the Law}

Article 12 of the UNCRPD reaffirms the state's obligation to recognise disabled individuals as being equal to non-disabled individuals under law. ${ }^{87}$ To fulfil this obligation, the state must build appropriate and effective safeguards to prevent abuse in accordance with international human rights law. ${ }^{88}$ This ensures that disabled individuals are able to exercise their rights without undue influence and in accordance with their will and preference. ${ }^{89}$ In relation to decision-making regarding medical treatment, this would mean that a disabled individual's right to refuse medical treatment should be protected by the state to the same extent it is protected for non-disabled individuals. Further, if this right has been limited by the state, this limitation should apply for the shortest time possible and be subject to regular review by an independent and impartial authority or a judicial body. ${ }^{90}$

Article 12 of the UNCRPD has arguably been the most contentious article when it comes to implementation, especially in a mental health context. ${ }^{91}$ Therefore, the Committee released the Comment in an attempt to reconcile the ambiguity. ${ }^{92}$

\section{B General Comment No 1 and Supported Decision-Making}

The Comment begins by stating that legal capacity is a universal attribute and should not be denied based on someone's mental or decision-making capacity. ${ }^{93}$ The state should provide ways to help support people with diminished mental or decision-making capacity to exercise their legal agency. ${ }^{94}$ This support "should never amount to substituted decision making". ${ }^{55}$ Further, if there are decisions

86 Lang and others, above n 15, at 209.

87 United Nations Convention on the Rights of Persons with Disabilities, above n 6, art 12.

88 Article 12(4).

89 Article 12(4)

90 Article 12(4)

91 Bach and Kezner, above n 15, at 29.

92 See generally Dawson, above n 14, at 72.

93 Committee on the Rights of People with Disabilities General Comment No. 1, above n 6, at [8].

94 At [12].

95 At [16] (emphasis added) 
that need to be made to intervene in an individual's exercise of their legal capacity, this decision should never be made in the "best interests" relating to a person. ${ }^{96}$ Instead, third parties should attempt to interpret their "will and preference" as far as possible. ${ }^{97}$ It concludes by stating that all policies which "allow or perpetrate forced treatment" should be abolished, as they contravene this inherent right. ${ }^{98}$ Treatment decisions should only be made with the prior and informed consent of the individual. ${ }^{99}$

The Comment calls for a shift in decision-making models from substituted to supported decisionmaking. However, the Comment does not define what a supported decision-making model is. Drawing from disability and mental health literature, supported decision-making is a support system or a framework that allows for the legal agency of the individual to be respected regardless of their mental or decision-making capacity. ${ }^{100}$ It puts the individual's "will and preference" at the centre of the decision-making process, effectively engaging their legal agency and autonomy. ${ }^{101}$ It encompasses a range of formal and informal supports to disabled individuals to help them make important decisions. ${ }^{102}$ These supports, overall, attempt to create a relationship between third parties and a disabled individual, provide them with as much information as possible before they make their decision, and attempt to ascertain their "will and preference". ${ }^{103}$

\section{MHA and General Comment No 1}

As stated above, s 59 of the MHA employs a substituted decision-making model which, in light of the Comment, is the exact opposite of what states should be employing to fully recognise the rights of disabled individuals. This was highlighted in the Committee's first review of Aotearoa New Zealand's compliance with the UNCRPD when the Committee stated Aotearoa New Zealand should: 104

... take immediate steps to revise the relevant laws and replace substituted decision-making with supported decision-making. This should provide a wide range of measures that respect the person's

96 At [17].
97 At [17].
98 At [42].
99 At [42].

100 Douglass, above n 15 , at 51 .

101 At 51

102 At 51

103 Terry Carney "Participation and Service Access Rights for People with Intellectual Disability: A Role for the Law?" (2013) 38 J Intell Devel Disab 59 at 66.

104 United Nations Committee on the Rights of Persons with Disabilities Concluding observations on the initial report of New Zealand UN Doc CRPD/C/NZL/CO/1 (2014) at [22]. 
autonomy, will and preferences, and is in full conformity with article 12 of the Convention, including with respect to the individual's right, in his or her own capacity, to give and withdraw informed consent, in particular for medical treatment ... consistent with the Committee's general comment No. 1 (2014) on equal recognition before the law.

Since the recommendation by the Committee, the New Zealand Government has not materially altered the law to employ supported decision-making models. However, the New Zealand Government did announce it was going to repeal and replace the MHA. In the interim, it has released updated guidelines to encourage clinicians to apply art 12 of the UNCRPD when administering treatment under the MHA. These guidelines are limited, as they can only be applied within the context of the MHA and are completely discretionary. Therefore, in practice, there have been no material changes in the way treatment decisions are made under the MHA. A shift in the law needs to be put in place in order for the New Zealand Government to live up to its commitments under the UNCRPD.

If the MHA were to move away from substituted decision-making to a supported decision-making framework, a paradigm shift from "best interests" assessments to "will and preference" assessments is needed. The next part focuses its analysis on the paradigm shift from "best interests" to "will and preference" and evaluates whether this shift is desirable.

\section{ANALYSIS: TOWARDS A BALANCED APPROACH}

Neither the current approach under the MHA nor the approach proposed by the Comment provide an appropriate solution. This part shows that adopting either approach is inappropriate for an Aotearoa New Zealand mental health context. It then advocates for a balanced approach which puts rights at the centre of the decision-making process (unlike the current approach under the MHA) but has more protective measures in place and more diverse perspectives on autonomy than present in the approach proposed by the Comment.

\section{A Evaluating the MHA in Light of the New Zealand Government's Commitments under the UNCRPD}

From the Committee's standpoint, the MHA is not compliant with the New Zealand Government's commitments under the UNCRPD due to the limitations substituted decision-making and "best interest" assessments have on a disabled individual's autonomy and their right affirmed under art 12 of the UNCRPD. However, law in Aotearoa New Zealand recognises that limitations can be placed on rights so long as such limitations can be "demonstrably justified in a free and democratic society". ${ }^{105}$ Proportionality lies at the heart of this assessment. ${ }^{106}$

105 New Zealand Bill of Rights Act 1990, s 5 .

$106 R$ v Hansen [2007] 3 NZLR 1 (SC) at [70]; and Moonen v Film and Literature Board of Review [2000] 2 NZLR 9 (CA) at [18]. 
As foreshadowed earlier, the justification for "best interest" assessments under s 59 is not strong enough to legitimately restrict the rights affirmed under art 12 of the UNCRPD. Further, the safeguards the New Zealand Government committed to putting in place under the UNCRPD, when restricting disabled individuals' rights, are lacking under the MHA. The "best interest" standard can no longer legitimately be used under the MHA - a new decision-making regime is needed.

\section{Protection from harm and the "serious danger" standard}

In his analysis of "serious danger", Kris Gledhill highlighted that the current interpretation taken by the courts and the Tribunal discriminates against people with mental illnesses: this approach directly contravenes the New Zealand Government's commitments under art 12 of the UNCRPD. ${ }^{107}$ Gledhill explains that when looking at normal ways to prevent harm from third parties in a criminal law context, the criminal law works on a basis that incarceration "should be reserved for situations where the level of harm caused or risked is high, which justifies the loss of liberty involved" ${ }^{108} \mathrm{He}$ further argues the loss of liberty under the MHA may be more significant than under the criminal law due to the potential for CTO to become indefinite. ${ }^{109}$ This makes the interpretation of serious danger in earlier case law, such as $J K$, more attractive to rationalise compulsory treatment as the standard for state intervention is the same for disabled and non-disabled individuals.

This discriminatory treatment of mentally ill individuals can also be seen when comparing the Government's response to Covid-19 to treatment under s 59 of the MHA. Faced with Australia's proposal to make the eventual Covid-19 vaccine mandatory, ${ }^{110}$ the New Zealand Government discussed whether it would follow suit. ${ }^{111}$ Analysing the consequences of Covid-19 in light of the test for serious danger under the MHA, there is an arguable case that a compulsory vaccine could be justified. If an individual chooses not to be vaccinated, there is a high chance they could face the serious health impacts of Covid-19 and spread this disease to other people, also impacting their health. Overall, the serious danger standard to justify compulsory treatment would be met. However, Prime

107 Kris Gledhill "Risk and Compulsion" in John Dawson and Kris Gledhill (eds) New Zealand's Mental Health Act in Practice (Victoria University Press, Wellington, 2013) 62 at 69.

108 At 69

109 At 69.

110 "Covid-19 vaccine likely to be mandatory in Australia" (19 August 2020) RNZ <www.rnz.co.nz>; and "Covid-19: Experts say laws allow vaccine to become mandatory in Australia" (20 August 2020) RNZ <www.rnz.co.nz>.

111 Claire Breen "Should a COVID-19 vaccine be compulsory - and what would this mean for anti vaxxers?" (7 August 2020) The University of Waikato <www.waikato.ac.nz>. 
Minister Jacinda Ardern confirmed that the vaccine will not be mandatory and that those who do not choose to be vaccinated will be doing so at their own risk. ${ }^{112}$

When comparing the response to people with mental illness and the response to the general population with Covid-19, a majority of this population not being disabled, it shows this serious danger standard is discriminatory. It works on the basis of a diagnosis of mental illness, as in other aspects of life when this serious danger test is met, a non-disabled person would not be subject to some form of state intervention. Overall, it shows that disabled and non-disabled individuals are treated differently under the law, going against the rights affirmed in art 12 of the UNCRPD.

\section{Parens patriae and the "self-care" standard}

The "self-care" standard contravenes the commitments under the UNCRPD as the standard embraces discriminatory models of disability. Both the UNCRPD and New Zealand's Disability Strategy 2016-2021 have affirmed that disability is not a strict medical issue, it is what happens when environmental factors do not cater for a diverse range of individuals. ${ }^{113}$ The self-care standard converts areas of social dysfunction into individual problems; embracing older discriminatory models which describe disability as an individual issue even though it is now recognised as an environmental issue.

The objective test which is apparent under the self-care standard can be discriminatory against mentally ill individuals. Social theorists have highlighted an issue called "liquid" modernity, in which social and economic contexts change at a rapid rate. ${ }^{114}$ The World Health Organisation has described this state of affairs as a challenge to health promotion as these changes can affect working conditions, learning environments, family patterns and the cultural and social fabrics of communities which can overall impact the wellbeing of individuals. ${ }^{115}$ Using this idea of "liquid" modernity, Matthew McKillop has observed that in a "liquid life" societal changes may impact an individual's social functioning. Applying this to a mental health context, these societal changes could in turn make individuals more susceptible to compulsory treatment. ${ }^{116}$ Therefore, the self-care standard means that environmental factors will be viewed as an individual problem as opposed to a societal problem. Overall, this goes against modern models of disability and promotes discriminatory treatment.

112 "Mandatory Covid-19 vaccine: NZ and Australia's different approaches" (19 August 2020) 1 News <www.tvnz.co.nz>.

113 United Nations Convention on the Rights of Persons with Disabilities, above n 6, at 1; and Office for Disability Issues, above n 85 , at 12 .

114 Zygmunt Bauman Liquid Times: Living in an Age of Uncertainty (Polity, Cambridge, 2007) 1-4.

115 Bangkok Charter for Health Promotion in a Globalized World (agreed by participants at the 6th Global Conference on Health Promotion, 7-11 August 2005).

116 McKillop, above n 66, at 90. 
Further, "best interests" assessments cannot be legitimately justified by the self-care standard as best interests assessments do not protect vulnerable individuals. As earlier explained the self-care standard can be traced back to parens patriae which puts an obligation on the state to protect those who cannot protect themselves. Recent evidence suggests that making people subject to involuntary treatment has only exacerbated concerning behaviours, whilst supported decision-making models generally have positive impacts on outcomes. ${ }^{117}$ For example, Sarah Gordon, when reflecting on her own personal experiences under compulsory treatment, highlighted that when she was subject to substituted decision-making and forcefully given medication, it had long-term negative impacts on her mental wellbeing. ${ }^{118}$ On the other hand, when she experienced collaboration with her responsible clinician and was engaged in the decision-making process, she had a much more positive experience. $^{119}$

\section{Safeguards under the MHA}

Section 59 under the MHA also cannot be justified in a human rights context due to the lack of safeguards in place for individuals who are subject to compulsory psychiatric treatment. Under art 12 of the UNCRPD, the New Zealand Government made a commitment that if it were to restrict a disabled individual's right to be recognised as equal under the law to their non-disabled peers, this would be for the shortest time possible with regular independent review. ${ }^{120}$ However, the review mechanisms that do exist under the MHA are lacking.

As outlined in Part One, there are three different review stages before a CTO is issued: but once the CTO is issued, there is no review by an independent body for six months. ${ }^{121}$ During the first month of this six-month period, the individual's art 12 rights are the most severely restricted as there is no engagement with their decision-making capacity or legal agency. ${ }^{122}$ Within this first month there will be no review from an external independent body. ${ }^{123}$ After this month, the individual under a CTO needs to consent to treatment and only at this point is the individual's autonomy respected. ${ }^{124}$

Although arguable that the second opinion given by a psychiatrist provides an adequate pathway for reviewing an individual's treatment under a CTO, the review is far from independent due to the

117 Mirfin-Veitch, above n 15, at 28.

118 Gordon, above n 16, at 269.

119 At 269 .

120 United Nations Convention on the Rights of Persons with Disabilities, above n 6, art 12(4).

121 Mental Health (Compulsory Assessment and Treatment) Act 1992, s 33.

122 Section 59(1).

123 Section 59(1).

124 Section 59(2). 
general bias that exists towards approving the proposed treatment. An audit of second opinions given under s 59 of the MHA found most second opinions approve treatments recommended by the responsible clinician. ${ }^{125}$ This audit highlights that the silence of the MHA as to what happens if a psychiatrist does not approve the treatment creates a bias towards approval. ${ }^{126}$ This is first because if treatment is denied, under the CTO, the responsible clinician is still under an obligation to treat the patient; thereby putting further pressure on the responsible clinician to find an alternative treatment. ${ }^{127}$ This extra pressure would be known to the psychiatrist giving the second opinion. ${ }^{128}$ Secondly, the second decision can be reviewed, and thus reversed, by another psychiatrist appointed by the Director. ${ }^{129}$ Finally, the psychiatrist giving a second opinion does not have an ongoing obligation to the patient, like the responsible clinician, and may not have as much knowledge of the patient's needs. ${ }^{130}$ This may make them more likely to approve the treatment recommended by the responsible clinician.

The new guidelines published by the Ministry of Health regarding practice under the MHA highlight the issue of bias within the second opinion given by a psychiatrist. However, the guidelines do not take any practical steps to try and combat this bias. The guidelines encourage that the second opinions are "free of conflict of interest and bias", however, do not discuss any steps that can be taken to address the reasons this bias exists in the first place. ${ }^{131}$ Therefore, the new guidelines do not do much to ensure that there are adequate safeguards under the MHA, speaking to the need for legislative change.

An individual under a CTO has the right to have their compulsory treatment under s 59 judicially reviewed, which arguably fulfills the New Zealand Government's commitments under the UNCRPD. Various barriers prevent this from being a realistic option, however. According to the United Nations Working Group on Arbitrary Detention, despite legal advice being guaranteed under the MHA, people undergoing compulsory assessments are often unrepresented as they do not have access to legal aid. ${ }^{132}$

125 John Dawson and others "Mandatory Second Opinions on Compulsory Treatment" in John Dawson and Kris Gledhill (eds) New Zealand's Mental Health Act in Practice (Victoria University Press, Wellington, 2013) 229 at 245 .

126 At 235.

127 At 234-235.

128 At $234-235$.

129 At 234-235.

130 At 234-235.

131 Ministry of Health, above n 18, at 5.

132 Sarah E Gordon and Anthony O'Brien "New Zealand's mental health legislation needs reform to avoid discrimination" (2014) 127 NZ Med J 55 at 58. 
This lack of access to independent review of an individual's condition and the restriction of their rights, show that the New Zealand Government is not fulfilling its obligations under the UNCRPD.

\section{Summary}

In summary, substituted decision-making and "best interest" assessments cannot be justified in a human rights context. The justifications for these best interest assessments are inherently discriminatory. Further, the MHA does not live up to the New Zealand Government's commitments under the UNCRPD. Not only do the justifications allow for unequal treatment of disabled and nondisabled individuals under law, but the limitations placed on this right of the individual's autonomy are not subject to regular independent review.

\section{B Evaluating the Comment in an Aotearoa New Zealand Mental Health Context}

Though the New Zealand Government's current approach is unacceptable, it should not adopt the recommendations in the Comment completely. The Comment takes an absolutist approach and tends to miss the reality of mental health in Aotearoa New Zealand.

The Comment fails to recognise that limitations on an individual's liberty can be justified. This oversight can be dangerous when applied to a mental health context as it could potentially create worse situations for mentally ill individuals. Limitations on individual liberty can be justified, which happens in everyone's life regardless of disability status. ${ }^{133}$ For example, if a mentally ill individual exhibits behaviours which create an imminent and serious threat of physical harm to themselves or others, it could be justifiable to make them subject to compulsory treatment to ensure society is protected from harm. This is justifiable because people without mental illnesses will be subject to similar preventative treatment if they exhibit those same behaviours. This also means subjecting mentally ill persons to compulsory treatment is not necessarily discriminatory. If substituted decisionmaking models and best interest assessments are never used in a mental health context, as the Comment advocates, it could mean that people suffering mental illnesses could refuse treatment to help control their dangerous behaviours and could potentially act in a way that creates a worse situation than compulsory psychiatric treatment (for example, being criminally convicted). ${ }^{134}$

The Comment also does not seem to take into account the decision-making capacity of an individual. In some situations, it may not be appropriate to allow individuals to make decisions due to their limited decision-making capacity. ${ }^{135}$ If an individual cannot process the information given to

133 New Zealand Bill of Rights Act 1990, s 5.

134 Dawson, above n 14 , at 72 .

135 At 73 . 
them regarding a decision, it would be inappropriate for them to make that decision themselves. This is another reason why the Comment should not be fully adopted in Aotearoa New Zealand.

The Comment is also silent on indigenous perspectives of autonomy. The most recent report on mental health services in Aotearoa New Zealand highlighted that Māori were disproportionately overrepresented in compulsory assessment and treatment under the MHA. ${ }^{136}$ Therefore, when it comes to decision-making processes under the MHA, Māori perspectives need to be taken into account. The UNCRPD and the Comment recognise that indigenous people are a vulnerable group within the disability community. ${ }^{137}$ However, the UNCRPD and the Comment do not include indigenous perspectives - they instead privilege the Western view of autonomy. ${ }^{138}$ The Comment expresses autonomy, and the right of legal capacity in individual terms, however, indigenous perspectives recognise collective rights alongside individual rights. ${ }^{139}$ In te ao Māori, family and whānau are the building blocks of Māori society. ${ }^{140}$ Decisions are not always made by the individual who is affected, but rather they are made as a group. This would be seen as substituted decisionmaking, and unacceptable in light of the Comment. In te ao Māori this would be a tikanga practice which raises the wellbeing, capability and resilience of whānau. ${ }^{141}$ This would be important for the individual's recovery.

Overall, the Comment has pitfalls which makes adopting it completely an inappropriate decision if society wants to protect vulnerable individuals in an Aotearoa New Zealand mental health context. Any approach going forward needs to put rights at the centre, as the Comment suggests, but still allow for justified limitations on an individual's rights to ensure protection of the individual and provide space for te ao Māori; ensuring that those who are impacted by mental illness are adequately represented in any strategy moving forward.

\section{A Balanced Approach}

A balanced approach which puts rights at the centre while still providing for justified rights limitation and te ao Māori is needed to help mentally ill individuals in Aotearoa New Zealand. For

136 Ministry of Health Office of the Director of Mental Health and Addiction Services Annual Report 2017 (February 2019) at 34.

137 Huhana Hickey and Denise Wilson "Whānau Hauā: Reframing disability from an indigenous perspective" (2017) 6 Mai Journal 82 at 87.

138 At 87.

139 See Decleration on the Rights of Indigenous Peoples GA Res 61/295 (2007), art 1.

140 Te Puni Kōkiri Understanding whānau centred approaches: Analysis of Phase One Whānau Ora research and monitory results (2015) at 17.

141 He Ara Oranga, above n 1, at [3.4.3]. 
the reasons stated above, neither the current approach under s 59 of the MHA nor the approach proposed by the Comment achieve this balanced approach.

This approach is different to the current process under s 59 of the MHA, as substituted decisionmaking would not be the default approach when making decisions about psychiatric treatment. Under this approach, the default model to use under this framework would require free, prior and informed consent of the individual before any treatment is administered. In order to obtain consent, formal supports should be put in place to guide the decision and ascertain the individual's "will and preference". This should include informing the individual about potential treatment options, effects of this treatment and how this may help them improve their condition. Other external support mechanisms should also be put in place. This includes ensuring other aspects of modern living are designed to ensure that diverse groups of individuals can access them. This would include housing, education and employment programmes to help those with mental illnesses to have a minimally acceptable standard of life. This would help combat the negative impacts of "liquid" modernity and prevent individuals from being subject to compulsory psychiatric treatment due to social dysfunction. These suggestions embrace the supported decision-making framework the Comment calls for and align Aotearoa New Zealand's mental health laws with its obligations under the UNCRPD.

However, this balanced approach would also differ from the suggestions in the Comment by still allowing for substituted decision-making in specific circumstances. It embraces the justifications for substituted decision-making under the MHA but increases the standards for these justifications to ensure they are non-discriminatory and legitimate. A substituted decision-making framework should be adopted if an individual's will and preference would result in behaviour which creates imminent and serious harm to themselves or others. This harm should be actual, or threatened, physical harm. Therefore, it would adopt earlier interpretations of serious danger, such as the interpretation in $J K .{ }^{142}$ This would make the serious danger test non-discriminatory as the same standard can be applied to people without mental illnesses.

Further, substituted decision-making should be used if upholding an individual's will and preference would prevent them from caring for themselves. However, the interpretation of self-care should take into account the idea of "liquid" modernity. Health professionals, when assessing an individual's condition, should consider whether the individual cannot care for themselves due to their condition or whether it is social dysfunction which is preventing an individual from having a minimally accepted standard of living. This would require a holistic approach from all social services but would ensure that individuals are not being subject to compulsory treatment due to social dysfunction. If it is external factors that are preventing an individual from having a minimally accepted standard of living, there should be a support system set up to help individuals with these barriers to accessing modern life.

$142 \operatorname{Re} J K$, above n 69, at 702. 
Finally, substituted decision-making should be used if an individual's decision-making capacity is so significantly impaired that they cannot perform specific tasks, such as processing the information given to them in a supported decision-making process. This restriction would only be applicable to approximately one third of patients under a CTO. ${ }^{143}$ Within this limitation, if there has been any prior "will and preference" communicated by the individual before their disability deteriorated their decision-making capacity, this should be reasonably ascertained.

If any of the circumstances explained above arise and substituted decision-making is justified, then there should be more scrutiny and independent review in place than there is currently under the MHA. The MHA should stipulate what happens if the psychiatrist providing a second opinion does not agree, and biases towards agreement should be combated. Further, reviews by the Tribunal and the Court should be allowed more often. Although there is an argument that this could exhaust judicial resources, if best interests and substituted decision-making assessments are only allowed in limited circumstances, then arguably, the amount of cases that need to be reviewed will be reduced. This would arguably make regular review more achievable.

Within this balanced approach, there should be constant communication with family and whānau, an explicit te ao Māori approach taken where appropriate, as well as constant independent review of an individual under a CTO. In order to develop a te ao Māori approach, partnership with Māori is essential to ensure the indigenous perspective is represented.

\section{CONCLUSION}

This article has shown that the New Zealand Government's current approach to psychiatric treatment does not promote and protect the rights of some of the most vulnerable people in society. However, it has highlighted the dangers of completely adopting the approach proposed by the Comment. The approach this article proposes helps set a balance between the two. It ensures that mentally ill individuals have the right to make decisions under mental health law subject to justifiable limitations upon these rights if such decisions create a serious danger to the individual or others, significantly impacts their standard of living, or would be inappropriate to follow due to the individual's decision-making capacity. Furthermore, this approach allows for greater independent scrutiny and provides space for te ao Māori. The New Zealand Government has a responsibility to help those who need it while also ensuring that their rights are still upheld.

143 Skipworth, above n 13, at 218; and Human Rights Commission "Mental health and human rights in New Zealand" (2018) <www.hrc.co.nz>. 